\title{
Combating Unemployment in Pakistan
}

\author{
SABUR GHAYUR
}

\section{INTRODUCTION}

The labour absorptive capacity of the economy is not keeping pace with labour supplies. An almost stagnant annual demand, estimated on the basis of the last few labour force surveys as ranging between 700,000 to 800,000 annually, is now being left far behind by a labour force whose stock is being added by over a million annually. ${ }^{1}$ This phenomenon is building up pressure on the domestic labour market. ${ }^{2}$ This situation, however, does not seem to be fully explained by the arguments of: (i) a net-return flow in overseas migration, (ii) saturation in the public sector employment, (iii) increasing capital intensity in the organised manufacturing sector, especially in its large-scale units, and (iv) worsening landman ratio in Pakistan's agriculture. Most of them, in fact, are the outcome of the absence of sufficient and meaningful considerations on employment and manpower development in the whole process of development planning and setting sectoral priorities. Otherwise emergence of this negative situation, to a large extent, could have been avoided.

Fortunately, the problem of under-utilisation of manpower, though continuously on the rise, has not assumed such proportions as could not be addressed by appropriate policy interventions. But a further delay in evolving concrete remedial measures, certainly, can lead to the point of no return. This then would be counter-productive and disruptive socio-economically.

The author, in this paper, attempts to indicate the existence of possibilities of generating gainful employment opportunities in some sectors/sub-sectors and regions of the economy as well as for certain target groups. In suggesting measures,

Sabur Ghayur is a Former Consultant of the National Manpower Commission, is presently associated with the Pakistan Office of the German Friedrich Ebert Stiftung Foundation as its Scientific Expert and Programme Coordinator.

Author's Note: I would like to acknowledge the excellent secretarial assistance provided by Mr Rashid Malik. An earlier version of this paper was prepared by me for the Prime Minister's Committee for Research and Analysis on the request of the Committee's Chairman.

${ }^{1}$ For demand and supply flows of the labour force, see Ghayur (1990) pp. 127-134 and National Manpower Commission (NMC) (1989) Chapters 1 and 5.

${ }^{2}$ The under-utilisation of the labour force in the form of unemployment, under-employment and dissatisfaction with the present work/job has been estimated to be affecting a quarter of the labour froce, [see, NMC (1988), p. 9]. 
an attempt is also made to make use of some of the recommendations of the Report of the National Manpower Commission (NMC). The approximate price tag for a number of the suggested measures is also indicated. A broad framework is also given for the institutional machinery needed for proper employment and manpower development planning. These suggested measures, however, presupposes that the present process of three D's namely deregulation, decentralisation and denationalisation would be vigorously pursued and effectively implemented.

\section{COMBATING UNEMPLOYMENT}

While suggesting an outline of the measures aimed at enhancing productive employment opportunities across regions and sectors of the economy, two considerations and one assumption are taken into account. First, the inability of the public sector in providing significance employment opportunities under the present state of affairs is clearly realised. This sector can generate additional employment opportunities only in the social sector. This phenomenon does indicate the possibilities of greater absorption of the educated and trained manpower, still a scarce commodity ${ }^{3}$, in the public sector. Here the limiting factor obviously is the availability of the finances and the trained manpower. Second, the informal sector in urban areas and the non-form sector in rural areas need to be properly developed for exploiting their employment potential. The accompanying assumption is the successful completion of the process of the three D's in Pakistan. The possibilities of generating productive employment opportunities are discussed as under: ${ }^{4}$

- Employment for the educated;

- Employment generation in rural areas;

- Employment generation in urban areas;

- Promoting overseas migration; and

- Strengthening the institutional machinery for employment and manpower planning.

\section{Employment for the Educated}

The problem of unemployment of the educated, these being defined as possessing at least a Secondary School Certificate, in terms of numbers is still small. Hence is amenable to proper measures aimed at removing the causes. This problem mainly owes its existence to a malfunctioning of the education and training system

${ }^{3}$ The educated labour force, matriculates and above, is 12 percent of the total labour force, see Ghayur (1990).

${ }^{4}$ Some of the suggested measures also appear in NMC (1989), mainly due to the association of the author with the National Manpower Commission and in its report writing. 
and also of the aspirations of the educated for white collar jobs, particularly in the public sector. The suggested measures, therefore, address themselves to these problems and constraints.

The imbalances in the demand and supply for the current flows, constructed by the author under two supply scenarios for different level of educated manpower (Table 1) are mainly concentrated amongst the matriculates and intermediates, $41,000-69,000$. The graduates appear to be marginally surplus, while post-graduates under the present trend of their output are estimated to be in short supply. ${ }^{6}$

\section{Table 1}

Imbalances in the Supply-Demand Flows of the Educated Labour Force in 1987-88

\begin{tabular}{|c|c|c|c|c|c|}
\hline \multirow[b]{2}{*}{$\begin{array}{l}\text { Educational } \\
\text { Level }\end{array}$} & \multicolumn{2}{|c|}{ Supply } & \multirow[b]{2}{*}{ Demand } & \multicolumn{2}{|c|}{ Imbalance } \\
\hline & $\begin{array}{c}\text { Low } \\
\text { Scenario }\end{array}$ & $\begin{array}{c}\text { High } \\
\text { Scenario } \\
\end{array}$ & & $\begin{array}{c}\text { Low } \\
\text { Scenario }\end{array}$ & $\begin{array}{c}\text { High } \\
\text { Scenario } \\
\end{array}$ \\
\hline Matric & 91 & 109 & 71 & 20 & 38 \\
\hline Intermediate & 57 & 67 & 36 & 21 & 31 \\
\hline Graduate & 30 & 37 & 29 & 1 & 8 \\
\hline Post-graduate & 12 & 12 & 13 & -1 & -1 \\
\hline Others & 20 & 21 & 12 & 8 & 9 \\
\hline Total & 210 & 246 & 161 & 49 & 85 \\
\hline
\end{tabular}

\section{Employment for the Matriculates and Intermediates}

The problem of the matriculates and intermediates, the largest segment of the educated unemployment, can be addressed by promoting self-employment and also encouraging them to go for training in employable skills. Efforts are needed to promote, through concessional credit, at least 20,000 self-employment opportunities. These opportunities should be based on a careful study of market needs of different areas and the credit be disbursed accordingly. The credit should be linked with intensive short-term training on the basics of book-keeping, store management, how to open a shop/undertake an activity and how to handle the correspondence. The amount of loan should be region-and activity-specific, but should not be large otherwise its mis-utilisation would occur. An average loan of

${ }^{5}$ For details, [see NMC (1989), Chapter-V.]

${ }^{6}$ For a study on (i) patterns of enrolment and output at different levels of education, and (ii) demand for and supply of educated labour force at different level, see Ghayur (1990). 
Rs 45,000 would be sufficient to undertake a number of self-operated small-scale activities. ${ }^{7}$ If it is assumed that the cost of loan administration and training per loanee would be Rs 5,000, then this proposal would need an amount of Rs 1,000 million, Rs 900 million for credit and Rs 100 million for administration and training staff.

Directing 7,000 of the matriculates and intermediates towards para-medical training (NMC, 1989) besides meeting the acute shortages prevailing in this field, would also help in reducing the problem of the unemployment. The unemployed can be attracted for this training by a monthly stipend of Rs 1,000 for six months. This would cost Rs 40 million."

Directing 2,000, towards training in office management practices (NMC, 1989) would promote employment in the private sector. A monthly stipend of Rs 1,000 for six months costing Rs 12 million ${ }^{9}$ would provide incentive for the unemployed to go for this training.

Directing 10,000 unemployed towards teacher training to meet the shortages and planned expansion of primary schools (NMC, 1989), would also help in reducing the unemployment of this target group. With a monthly stipend of Rs 1,000 it would cost Rs 130 million annually. ${ }^{10}$

\section{Employment of the Graduates and Post-graduates}

The problem of unemployment of the graduates and post-graduates is small and owes its existence to low quality of education, mismatches and aspirations of the educated for specific jobs.

About 1,000 graduates need to be pursuaded to go for further studies especially in the science and technology (S\&T) disciplines. A monthly stipend of Rs 1,000 for two years would serve as a good attraction and cost Rs 12 million annually. Similarly, attracting 500 post-graduates for pursuing higher studies in S\&T fields by giving Qarz-e-Hasna loan besides reducing the shortages of such personnel would help in enhancing their employability.

Encouraging graduates and post-graduates, about 750, to establish their own enterprises by giving loans, besides solving their problem of unemployment would result in additional employment opportunities. These loans need to be integrated with intensive short-term training on how to run an enterprise, basic accounting,

${ }^{7}$ For details on the required initial investment for a number of activities [see, Chaudhry and Khan (1990), pp. 12-14.]

${ }^{8}$ Additional costs of training should be minimum as existing facilities are proposed to be utilised in an optimum fashion.

${ }^{9} 10$ Additional costs of training should be minimum as existing facilities are proposed to be utilised. 
correspondence and personnel management. At the rate of Rs 150,000 per person this would cost an amount of Rs 112.5 million.

Encouraging the post-graduates to undertake their own consultancy firms by making available to them concessional credit, besides their own employment, also has the potential of absorbing some of the other unemployed.

\section{Employment of the Professional Manpower}

The unemployment of the professionals especially of the engineers and doctors, is small in number. While for the doctors it mainly reflects their choices especially of the area, lack of practical training and mismatches between demand and supply are the main reasons for the unemployment of the engineers in Pakistan. The employment of the engineers can be promoted by encouraging about a 1000 of them to undergo practical training in large establishments. This can be ensured by giving them a stipend of Rs 4,000 per month. This proposal would cost Rs 48 million annually. Similarly, the engineers, about 250 , can also be encouraged to establish their own enterprises and consultancy firms. This can be facilitated by giving them loans up to a maximum limit of Rs 500,000 . This would cost Rs 125 million annually. A specific number of the engineers can be pursuaded to go for higher studies and for this they can be provided Qarz-e-Hasna.

For the employment of the doctors, which in fact is mainly because of their choices, can be addressed by making a three-year service in rural areas for the fresh graduates mandatory for appointments in teaching hospitals/government hospitals, granting scholarships for higher studies and also giving medical practice certificate. Similarly, the doctors also need to be encouraged to go for higher studies by providing Qarz-e-Hasna loans. The doctors can be encouraged to establish their own private clinics/hospitals by providing them loans and concessions on imports of equipment/machinery. Providing loans to 250 doctors at Rs 500,000 per doctor would cost Rs 125 million.

\section{EMPLOYMENT IN THE URBAN AREAS}

The suggestions made for enhancing employability of the educated in previous section would also result in generation of employment in urban areas. The following additional measures would generate further employment in urban areas:

\section{Development of the Urban Informal and Small-scale Sector}

About 10,000 skilled workers should be encouraged to get themselves absorbed in the urban informal and small-scale sector. This can be promoted by identifying location-specific activities in the manufacturing, services and repairs, and linking it with loans ranging from Rs 10,000 to Rs 100,000 . An average loan 
of Rs 25,000 would cost Rs 250 million.

In order to develop small-scale manufacturing sector, attempts should be made to establish at least one small industrial estate with necessary infrastructural support in each city and big town. The private sector can be encouraged to take lead and develop them.

\section{Developing the Construction Sector}

In the urban areas attempts should be made to identify and develop new residential and commercial areas on self-financing basis. The construction sector is highly employment intensive and caters for skilled, semi-skilled and unskilled workers, a significant number of them being rural to urban migrants. With emphasis on this sector, other activities would also be encouraged, thereby leading to additional employment opportunities.

\section{Provision of Infrastructural Facilities in Low-income Areas}

Efforts also need to be directed for providing basic infrastructural facilities to low income/slum areas on a priority basis. This in turn would result in promotion of greater employment opportunities (NMC, 1989).

\section{EMPLOYMENT IN RURAL AREAS}

The suggestions made for enhancing employability of the educated in the previous section would also generate employment in rural areas. The following specific measures would further enhance employment opportunities in rural areas:

\section{Creation of Focal Points}

Basic infrastructural facilities, a prerequisite for initiating any economic activity, needs to be provided in selected villages. The Union Councils, for this purpose, can be made focal points. Facilities like electricity, a Basic Health Unit (BHU), telephone, a road link and a high school need to be made available at the level of each Union Council.

A market centre comprising of small shops, sales depots and repair and service facilities need to be constructed at the level of each Union Council. An initial governmental grant to a Union Council or to the concerned market committee can then help to sustain such activities on a self-financing basis.

\section{Establishing Rural Development Support Centres}

In a cluster of 15-20 Union Councils and their villages, certain areas can be easily identified where a road link with the main area is available. This area 
should be developed for establishing multi-purpose, well-integrated and comprehensive Rural Development Support Centres (RDSCs). The RDSCs, would serve as: (i) a basis for industrialisation; (ii) a marketing centre; (iii) a source of guidance and counselling, information and extension services; (iv) a centre for supply of inputs; (v) a centre for skills development and upgradation; (vi) a link with the large-scale manufacturing sector; (vii) a link with credit institutions; and (viii) a source of labour market information. These centres can be established with an initial governmental grant to enable their construction. But later on should work on a self-financing basis. These centres need to be run by their organising committees which would seek to generate additional funds required for maintenance and development.

Assuming that the cost of construction of a shop is Rs 150 per square foot and there would be 20 shops in each centre of the size of $10 \mathrm{C} 15$, then the cost of construction of one centre comes to Rs 450 thousand. If 250 such centres are to be built, then it would cost Rs 112.5 million. Besides creating employment in the construction phase, such centres have the potential to generate significant income and employment opportunities.

\section{OVERSEAS MIGRATION}

Notwithstanding the changed environment in the Middle Eastern countries, for a long time to come, they would continue to be dependent on foreign workers. Efforts are to be made to get a larger share of the declining demand. A target of sending 100,000 workers annually would not be unrealistic. But this would require concerted efforts in the form of: (i) making bilateral agreements especially with the Gulf Cooperation Council (GCC) countries and designing training programmes accordingly; (ii) entering into sub-contracting arrangements; (iii) getting catering and maintenance contracts; (iv) exploring new markets particularly in the Far Eastern countries and of Japan; (v) regular campaigns and visits to the importing countries; and (vi) exploiting the post-gulf war situation. An increasing role of private employment promoters can effectively help in achieving the target. Similarly decontrol over the process of out-migration would contribute significantly towards enhancing the annual flows overseas.

\section{STRENGTHENING OF INSTITUTIONAL MACHINERY FOR EMPLOYMENT AND MANPOWER PLANNING}

The main contributing factor for the existing low manpower utilisation pattern as well as mis-matches between demand for and supply of manpower, especially 
for the educated and trained, is the ineffective and weak institutional machinery for employment and manpower planning. In fact this machinery has failed to bring these issues to a central point in the whole process of economic development.

Despite growing unemployment, the questions that remain inadequately answered are: (i) how many are unemployed; (ii) who are they, the unemployed, what are their educational, social and regional background; and (iii) what are the occupations, trades and other activities which have potential for gainful employment in different areas, regions and locations. Absence of information on these variables is affecting proper manpower planning, leading to the development of an education and training system in complete isolation with the world of work. This is also affecting, on the one hand, in designing a proper system of employment counselling and vocational guidance and, on the other hand, in giving a proper feedback to the development financial institutions.

Such a scenario while clearly demonstrating the failure of existing machinery, highlights the need for its strengthening. This can best be achieved by: (i) making a full-fledged Ministry at the federal level responsible for employment, manpower and training having an effective say in the planning and decision-making process; (ii) making a coordinating agency at the federal level to consolidate, integrate and disseminate the information as well as monitor the changes occurring in the labour markets and to act as a training institution; and (iii) developing a four-tier system of labour market information (LMI), having Union Councils/RDSCs, Employment Exchanges, provincial Directorates of Manpower and Training, and Federal Coordinating Agency as its different tiers (NMC, 1989). This system, the LMIS, should have horizontal and vertical integration with all the concerned institutions and departments such as the credit/financial institutions, educational and training institutions, planning and development ministries/departments, the private sector and the NGO's.

\section{CONCLUSIONS}

A continuation of the present trends of stagnation in the demand for labour coinciding with increasing supplies, over a million annually, would be counterproductive and disruptive socio-economically. Hence a mechanism needs to be evolved whereby attempts are made to enhance gainful employment opportunities across different regions, sectors and target groups. This problem, the under-utilisation of manpower, though on the rise is fortunately not large and is amenable to

${ }^{11}$ For details about as how the institutional machinery and labour market information system can be developed, see NMC (1989) Chapters 12 \& 13 and Ghayur (1990 a). 
concrete policy formulations. But this would require concerted efforts, integrated and well-coordinated, towards designing and effective implementation of the policies, of which the creation of a conducive environment for investment, being the main one. Obviously such an exercise, would require greater participation by the private sector, NGOs and the Local Bodies. The process of the three D's would scrve as a necessary motivator and facilitator.

Such a policy environment is a prerequisite for exploiting the potential for a larger generation of employment opportunities being available in the form of: (i) public social sector; (ii) self-employment; (iii) urban informal and small-scale sector; (iv) rural non-farm sector; (v) construction sector; and (vi) overseas migration. An effective employment and manpower planning machinery would facilitate in inserting human resource development issues in the very process of development planning and its implementation. Such machinery would also lead to effective vocational guidance, employment counselling and a meaningful feedback to credit institutions, and education and training systems. Such considerations build an environment conducive to the generation of productive employment opportunities, dispersed fairly in different regions, thereby effectively combating unemployment.

\section{REFERENCES}

Chaudhry, Hafeezur Rehman, and Salahuddin A. Khan (1990) Socio-economic Conditions of the Self-employed. A study sponsored and supervised by Friedrich Ebert Stiftung for the Ministry of Manpower and Overseas Pakistanis. Islamabad.

Ghayur, Sabur (1989) Educated Unemployed in Pakistan: Estimates of Imbalances in the Current Flows. The Pakistan Development Review 28:4. Ghayur, Sabur (1990) Employment of the Educated: Consideration on Patterns of Supply, Demand and Imbalances. In S. N. Hyder (ed) Employment Issues in Pakistan; Review of Some Evidences. Islamabad: Pakistan Manpower Institute.

Ghayur, Sabur (1990) Labour Market Information System in Pakistan: An Indepth Review of Existing Situation and Suggestions for Improvements. A Thematic paper prepared for the Ministry of Manpower and Overseas Pakistanis and ILO, and presented in the Three-Days ILO-FES-Manpower Division Tripartite Seminar on Upgrading Labour Market Information Capacity. 25-27 November, Islamabad.

National Manpower Commission (1988) A Strategy for Employment Promotion and Manpower Development in Pakistan. Interim Report of the National 
Manpower Commission, Islamabad.

National Manpower Commission (1989) Report of the National Manpower Commission. Islamabad: National Manpower Commission. 


\section{Comments on}

\section{"Combating Unemployment in Pakistan"}

The paper presented by Mr Sabur Ghayur deals with a crucial policy issue of the present times. This paper is an offshoot of an earlier paper presented by the author in an earlier meeting of the PSDE. This paper attempts to present the measures for combating unemployment in Pakistan.

From the title of the paper one gets the impression as the paper would deal with both open and hidden unemployment. But I was surprised to find out that the paper only focusses on open unemployment and neglects the under-employment of labour or hidden unemployment which ranges between 25 to 35 percent of the labour force. Given the fact that open unemployment in Pakistan ranges only 3-4 percent of the labour force, one is constrained to ask that should open unemployment really be considered a problem? If yes, then one would like to know that at which rate open unemployment starts giving trouble.

More specifically, the author constructs the demand and supply flows for the educated labour force (Table 1) to find out the imbalances which serve as the basis for the author's proposals in the rest of the paper. However, surprisingly no such imbalances are given by the author for the so-called uneducated labour force.

The demand and supply flows are known to be highly sensitive to the method of estimation. There have always been doubts about the validity of these estimates. However, the method used by the author is particularly very "crude" and of a primitive nature, especially in estimating the demand flows. More sophisticated techniques of demand forecasting are also available which are widely used in the literature. Therefore, it is quite surprising that the author has not utilised these techniques.

It also appears to me that the demand and supply flows given in Table 1 are also not comparable because the supply flows are only for a single year i.e. 1986-87, while the demand flows are increases in employment in 1986-87 over 1982-83, as given in the Labour Force Survey. Thus, the demand flows do not reflect the annual demand. I wonder how the author can treat this employment as an approximation for annual demand.

It is tempting to point out that the estimates for the demand and supply flows in Table 1 are made by the author in two of his earlier articles. Therefore, the reader is lost while trying to understand where these figures came from. These 
tables can conveniently be included in an annexure to the article.

The author proposes to spend about Rs 2 billion for the absorption of the unemployed educated labour force whereas no such scheme or allocations are proposed for the uneducated work force which constitutes 88 percent of the total labour force. Thus, his proposals tend to create a bias in favour of the educated work force which leads to the questioning of the credibility of his proposals. Moreover, the proposals presented by the author for combating open unemployment are only relevant for the imbalances in a single year i. e. 1986-87. Given a huge backlog of the unemployed before and after that single year one wonders how these proposals could be put into practice.

The propositions in the paper are conditional upon the implementation of deregulation, decentralisation and denationalisation policies of the government. However, the author has not explained the causal link of these policies with his own proposals.

In the end, I like to observe that the reasons why modern sector growth does not generate more jobs and why the labour force is rapidly expanding touch a whole gamut of development issues. The way the author treats open unemployment and tends to seek solutions for this problem seems to me too simplistic.

Abid A. Burki

Quaid-i-Azam University, Islamabad. 